\title{
The Adjustment of Curriculum: a New Experiment of College English Class
}

\author{
Jingnan Lyu \\ School of Foreign Languages Shaanxi Normal University, Xi'an, 710062, China \\ Email: 2028108247@qq.com
}

Keywords: College English Teaching; Curriculum; Technology-aided Teaching Mode

\begin{abstract}
English has long been viewed as the most important international language, which is widely used in communication as well as academic research. With the acceleration of Chinese modernization, global-oriented talents are urgently needed in almost all fields. College students are in the last stage to prepare themselves for future career, and English proficiency is a very important factor affecting their professional development. College English must help students equip themselves with essential abilities of learning and using English in the future life and career. The traditional two-year English course cannot cope with the present situation, so a four-year continuous curriculum aided with information technology and enhanced by knowledge about specialty will satisfy the new demand.
\end{abstract}

\section{Introduction}

In the 20th and 21st centuries, English language is generally considered as the most important international language, which is needed in various occasions, ranging from business conferences, political negotiations to personal activities like traveling and employment. Since 1978, English has become an indispensable part of educational curriculum in Chinese universities. And currently, it has dominated the context of foreign language learning and teaching. Its acquisition can guarantee the availability of opportunities to employment, traveling, higher education, and even better life (Crystal, 1997). In China, English proficiency has long been promoted as indispensable for the nation's modernisation and internationalisation though English is seldom used for daily communication [1]. The acquisition of this global language is more connected with various tests and certification than with practical application. Quite a large portion of Chinese EFL learners are learning English for passing certain level of tests, thus focusing more on the acquisition of particular skills needed in English tests. They may neglect daily application of the language as well as the beneficial effect of using English as a communicative tool for professional development. Facing this situation, teaching English for EFL learners, specially at college level, is a challenging task in China.

\section{Brief history and challenges of English language education since the late 1970's}

Near the end of 1970's, Chinese social reformation has begun and the government has carried out open policy. International communication has been more and more constant and important for Chinese modernization. Under this background, English language education has been a compulsory course in mainstream education from junior middle schools to universities ever since 1978. It has been one of the must for college entrance examination. In 1984, Ministry of Education organized a seminar on how to improve English language education, which can be viewed as the first turning point for college English teaching and learning. In the seminar, College English Test (CET) was set for an effective model of testing the acquisition of English learners at college level. Since 1986, College English Test has been held in national-wide range. After 1989, CET has been updated as CET-4 and CET-6, which have been kept until now. By the 1990's, few EFL learners choose to attend extracurricular English training programs. English is just taught as one of the major courses, and no more emphasis was attributed to it. 
As globalization has become a more influential trend and infiltrated into daily life of common people, international communication is much closer than ever before, and Chinese people are eager to know the outside world and introduce Chinese culture and new development to the whole world. In the new millennium, English language education was further expanded to primary schools, though in most of the rural area this goal was impossible to realize, because compulsory education were not even available to those children living in some remote and backward villages. Actually, from these years, the inequality of education resources has become more and more obvious. Statistics show that in 2002 the total investment in education was more than 580 billion RMB, 77\% of which was used in cities where less than $40 \%$ of the whole population were living, while the rest $60 \%$ of the whole population in the rural areas had to share $23 \%$ of the educational investment [2]. The inequality of educational resources has greatly influenced the quality of rural basic education, and English language education has unavoidably lagged behind. As a result, it is quite common for college students of the same class whose language proficiency may vary greatly, because they come from different areas.

While in the past ten years, children in primary schools have already been busy with learning this foreign language. Besides the courses required by schools, numerous training agencies began to offer various English classes, among which New Oriental, the most famous private education organization, and Li Yang's Crazy English have triggered enthusiasm of learning English of almost the whole nation. Nowadays, parents, educators and policymakers, making their efforts to prepare children for a multilingual future, put forward the concept of "the earlier the better" when it comes to learning a foreign language. In cities of China, it is not so unusual to see young children of 3 or 4 years old to attend English classes, and kindergartens featured by bilingual education are definitely regarded as a better choice by parents who are eager to train their children to be international-oriented talents. Considerable attention has been paid to English learning and teaching in our society, not just because it is a necessity for college entrance examination, but also because Chinese open policy has led the whole society to a wider world and English has become the essential means for people to contact with it. In terms of college English education, policy makers have made many reformations, including revising course syllabus and adjusting the contents of CET. Universities rearrange curriculum for a better effect, while researchers and teachers are eager to find out new teaching methods.

Since English has appointed as one of the compulsory curriculum in the late 1970's, English teaching methodology has been experiencing several major changes. The teacher-centered English class had been the dominant style since 1950s, aiming to equip students with grammar and vocabulary knowledge, rather than improving students' ability in using the language. As for college English class, teacher give lectures while students take notes. English, which should be a living language used in actual communication, is reduced into book knowledge. This point can be seen from CET, the national test, which focused on examining students' grammar and vocabulary knowledge. Languages, all alike, can be useful and acquired only when they can perform actual functions, such as in communication or transferring information. Traditional grammatical approach in English teaching cannot satisfy the needs of training global-oriented talents.

In the 1980s, communicative approach was introduced by Li Xiaoju and other English educators. In the following ten years, this approach has been successfully localized and enjoyed its golden age [3]. Student-centered English class gradually take place of the traditional teacher-centered lectures. However, in the new century, communicative approach has been viewed outdated by western educators. At the same time, Chinese educators have already realized the insufficiency of dealing with English only as a communicative tool. Task-based learning, which can be seen as a kind of updated communicative approach, has now dominated English class. The whole language approach aims at mastering language skills as well as developing the corresponding mode of thinking. Both teacher and student should be viewed as the core of class, thus neglecting either side must be wrong.

Since the inequality of education resources has not yet disappeared, despite of the efforts of the policy makers, the quality of English language education throughout the whole country will 
unavoidably differ. Thus, educators cannot apply the same approach for EFL learners at college level who come from various areas and whose mastering of the language may quite vary from each other. Considering the present large-sized classed in Chinese universities, it is impossible for English teachers to satisfy every student's needs. At the same time, most of the universities cannot scale down classes, because of lacking qualified English teachers. As a result, some students whose English are already reached higher level may feel disappointed with college English class. On the other hand, some students who do not have enough educational resources may find it hard to keep pace with the new changes in the language learning strategy. Both cases will finally lead to the lack of learning motivation.

One unforgettable fact must be pointed out here, that is, Chinese college students, who have already been trained for attending various tests for 12 years, cannot easily convert from test-oriented learning habits to quality-oriented ones. In addition, students need to master enough professional knowledge, preparing themselves for securing a job in the very competitive job market. Though English is not their major, they have to pass the national-organized CET, so that they can get a certificate as a proof of their academic performance. As a result, passing CET-4 and CET-6 becomes the first goal and primary motivation when it comes to learning English.

Nowadays, China is evolving from a 'localized nation' to an 'internationalized nation' [4], therefore the demands for talents are no longer the same as before. The 'internationalized nation' requires not only the foreign language talents who can simply use the language, but talents who can approach professional knowledge without English as a hindrance. In order to satisfy this demand, college English teaching has to lay greater emphasis on English for Academic Purposes (EAP). It is equally essential to improve student's language skills in general as well as acquisition of English for academic purposes. College English teachers have to find better way to cope with this new challenge.

\section{Specialty-oriented continuous curriculum and technology-aided class}

In the former section, I have reviewed the changes in educational policies and English teaching methodology in general, as well as the current challenges that are commonly met by college English teachers, and then I suggest a specialty-oriented continuous curriculum and technology-aided class will help to cope with those challenges faced by college English in present situation. Higher education is the last phase for young adults to prepare themselves for entering the real society and taking their future job. On one hand, they need to master enough professional knowledge which will directly serve their future career. On the other hand, they have to train themselves in all-round way, which definitely includes language proficiency. College students are mature enough to know why they are studying and their major may become the basis for the rest of their life. Considering the fact that college students are characterized by greater cognitive abilities and conceptual complexity, the learning materials for college English class should combine language skill training together with professional knowledge reflecting the main concepts of students' major, specialty in the field, branch of learning and their needs [5]. This will help students realize the usefulness of English as a means to get more professional information, thus they will not lay their attention to English tests only. Arousing students' learning motivation is an essential step to lead student to the way of life-long active learning.

However, as for college English teachers, it is quite natural for them to lack specific professional knowledge, because all the training they have received are about basic language skills: listening, speaking, reading, writing and translating in general. If the language materials are too professional in certain field, such as biology or chemistry, it will become a big challenge for the English teachers themselves.

So how should educators choose the suitable language materials to reach the balance between teaching and learning? Is it necessary to compile separate textbooks for each majors? Must college English teacher start to learn a new specialty so that they can teach non-English majors of different fields? I think the answer should be like this: Learning materials can consist of two kinds: One is the comprehensive textbooks, focusing on training language skills in general. The other kind is the 
professional textbooks, which consist of primers of the major and the introductory articles about the newest development. In this way, students' interest in English can be aroused and connect language proficiency with major studying, while English teachers will not be frustrated by professional knowledge other than language problems.

Since students are facing two types of learning materials, it is necessary to rearrange curriculum. In the first year of college, students have to adjust to the new life style, living in a strange place away from parents' supervision. Though they have more courses than when they are in high school, they do not feel so much pressure as before. With this newly-found freedom, most of students can be quite motivated in learning. So it is important to offer enough stimuli to keep them moving. Educators should divide students according to their levels of language proficiency, so that they can be offered suitable language courses. Students whose acquisition of English is better than the average level should be asked to attend classes of higher level and given more time to study independently under the supervision of teachers, while students whose language proficiency reach the average level will attend classes focusing on reinforce basic language skills to prepare for further study in the second year of college. As for those students whose English is below the average level, such as students majoring in physical education or music, it is necessary to arrange easier English courses and make up for fundamental grammar and vocabulary knowledge.

In the second year of college, the primers of specific major can be introduced into English classes. English classes for the second-year students should consist of two parts: One part is for training of basic language skills, while the other is to study the primers of specific major. Usually, it is until the third year that students get fully involved into further study of their major. Thus at this phase, offering students a glimpse of professional knowledge will help them better prepare for future study. College students' greater cognitive capabilities and conceptual complexity enable them to keep pace with this arrangement. Seasoned with specific knowledge of each major, students will use the foreign language more as a means of attaining information, not just skills of passing tests. With learning motivation greatly aroused, students will actively get immersed into language materials and get more language using experience, and their acquisition of English will consequently be improved.

Two-year English courses are the common practice in Chinese universities. However, in these two years, students are seldom prepared to use English for academic purpose, so it is necessary to prolong English courses to the third year of college. In this phase, students can be taught the general principle of writing academic paper in English and offered newest development in each major. Academic writing course and extensive reading on English media are suitable for the third-year students. Basic language skills are no longer the focus of English course, while the abilities of using the language to obtain information and conduct academic research are the major targets.

As for the four-year students, whose time and energy are mainly occupied by educational practice and job hunting, independent study should be a better choice. MOOC, Micro-class and seminar enable students to choose when and what they want to learn. The subjects can vary, including interpersonal relationship, career planning, as well as new trend in academic research.

With this continuous curriculum, students will be immersed into English and try to connect language learning with their major. Their learning motivation is not just for passing tests or getting certificate, but for professional study. They will learn how to apply this international language in their major and how to attain more information worldwide.

The popularization of computers has promoted the swift development and intensive use of information and communication technologies (ICT) in the educational process. It is one of the dominant trends in the development of modern educational practice in universities to use of electronic educational resources, and this is naturally affect the mode of foreign language teaching. Many oversea researchers are devoted in updating language teaching process with ICT. Pod casts technology provides the development of research skills and learning autonomy; webQuest technology is didactic means to form foreign language communicative competence; the network-based teaching package contributes to conscious activity and self-study promotion allowing to improve and develop students' information and learning competence [6]. 
Multimedia package can be viewed as the first try of applying new technology into EFL teaching. Nowadays, it has already become the dominant mode of college English class. With the help of multimedia equipment, teachers can present language materials more vividly and create a better language environment, while students may be easily attracted in terms of vision and audition.

Many universities are now engaging in set up network teaching platform, which grants leaning autonomy to students [7]. Students can choose when and what to learn according to their own performance and demands, while it is convenient and timely for teacher to add up-date information and new relevant teaching material or delete the inappropriate parts, which compensate the disadvantage of the time-consuming process of compiling textbooks. The network teaching mode combines different approaches in educational process, increasing the teaching density. For example, MOOC, Micro-class and any other modes can be part of the platform, offering students essential guidance. Administrators can also enhance inter-school communication in order to share excellent teaching resources, which will definitely enlarge students' horizon. With network teaching platform, students under self-control can actively design their own educational and developmental trajectory.

The continuity of English courses will guarantee students sufficient time to get involved in a foreign language, while the extra materials concerning about different majors may benefit their academic and cultural development. Id addition, information technology will make it possible for students to plan their personalized curriculum with greater flexibility.

\section{Conclusion}

The rapid development of Chinese society and the ever-increasing globalization and international communication impose a lot new problems in front of educators and policy makers. In spite of all the efforts made by theoretical researchers and EFL teaching practitioners, English language education at college level still have many problems to be solved. College students, as learners of higher cognitive abilities and conceptual complexity, need not only to learn a language for the purpose of developing the basic language skills, but also to use the language in promoting global-oriented communication and get a wider and further sight in major study. Their motivation, determination and career planning will definitely affect the process of their language learning. So it is obvious that administrators of universities must be more flexible and more responsive in curriculum arrangement. It is only in this way that teachers can really contribute to the success of their students' learning by creating an all-round environment positive to language application and help students master the language tool which will benefit their further progress after graduation.

\section{References}

[1] X. Gao. The study of English in China as a patriotic enterprise [J]. World Englishes, 2012 31(3) 351-365.

[2] No. 21 Seminar of the Administration of Education of China, The Equality of Education for Creating Harmonious Society [J]. China Higher Education Research, 2006(1) 26-28.

[3] Liquan Xiao, Reflection on Macro Teaching Approaches of English Education in China [J]. Foreign Language Education, 2005 26(5) 35-41.

[4] Li Yuming. Some Thoughts on Foreign Language Planning in China [J]. Journal of Foreign Languages, 2010 133(1).

[5] Mihaela Cozma, The Challenge of Teaching English to Adult Learners in Today's World. 7th World Conference on Educational Sciences [C]. Greece:Athens, 2015. 1209-1214.

[6] Elvira Sokolova, The Advantages of the Network-based Electronic Teaching Package by the Implementation of English for Specific Purposes Course. Russia: Tomsk, 2015. 193-198.

[7] Qinghong Zhao, Jinfen $\mathrm{Xu}$, Analysis of the College English Reformation: Empirical Study and New Trend [J]. Foreign Language World, 2011 142(1) 30-37. 